Bilddenken und Morphologie 



\section{Bilddenken und Morphologie}

Interdisziplinäre Studien über Form und Bilder im philosophischen und wissenschaftlichen Denken

Herausgegeben von

Laura Follesa und Federico Vercellone

\section{DE GRUYTER}


The book is part of the project TIM-Adrastea: Thinking in Images. Herder's Adrastea from 1801-03 up to Nowadays that has received funding from the European Union's Horizon 2020 research and innovation programme under the Marie Skłodowska-Curie grant agreement No 753540.

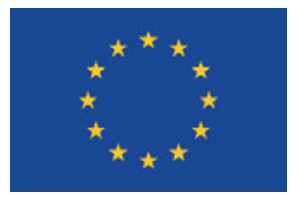

ISBN 978-3-11-067412-5

e-ISBN (PDF) 978-3-11-067419-4

e-ISBN (EPUB) 978-3-11-067433-0

DOI https://doi.org/10.1515/9783110674194

\section{(cc) BY-NC-ND}

Dieses Werk ist lizenziert unter einer Creative Commons Namensnennung-Nicht-kommerziell-Keine Bearbeitung 4.0 International Lizenz. Weitere Informationen finden Sie unter http://creativecommons. org/licenses/by-nc-nd/4.0/

\section{Library of Congress Control Number: 2021938410}

\section{Bibliografische Information der Deutschen Nationalbibliothek}

Die Deutsche Nationalbibliothek verzeichnet diese Publikation in der Deutschen Nationalbibliografie; detaillierte bibliografische Daten sind im Internet über http://dnb.dnb.de abrufbar.

(C) 2021 bei den Autoren, Zusammenstellung @ 2021 Laura Follesa und Federico Vercellone, publiziert von Walter de Gruyter GmbH, Berlin/Boston

Dieses Buch ist als Open-Access-Publikation verfügbar über www.degruyter.com

Umschlagabbildung: Glasmalerei: Innenraum, Glasfenster von Th. Nieuwenhuis für die Kunsthandlung Van Wisselingh en Co, Sammlung F. Leidelmeijer (Anmerkung: Fotografiert für Glas in lood in Nederland 1817-1968). (C) Rijksdienst voor het Cultureel Erfgoed Diese Abbildung ist lizenziert unter einer Creative Commons Namensnennung-Weitergabeunter-gleichen-Bedingungen 4.0 International Lizenz (CC BY-SA 4.0). Weitere Informationen finden Sie unter https://creativecommons.org/licenses/by-sa/4.0/

Druck und Bindung: $\mathrm{CPI}$ books $\mathrm{GmbH}$, Leck

www.degruyter.com 